\title{
A Survey of Clinicians Practice Patterns in Anticoagulation Therapy \& Prophylaxis in Nigeria
}

\author{
Raphael Anakwue ${ }^{1}$, Theresa Nwagha ${ }^{2 *}$, Ogba Ukpabi3 ${ }^{3}$ Ndudim \\ Obeka4, Emmanuel Onwubuya5, Uwa Onwuchekwa6, Benjamin \\ Azubuike $^{7}$ and Innocent Okoye ${ }^{8}$ \\ ${ }^{1}$ Department of Medicine, Pharmacology/ Therapeutics, University of Nigeria, Nigeria \\ ${ }^{2}$ Department of Haematology \& blood transfusion, University of Nigeria, Nigeria \\ ${ }^{3}$ Department of Medicine, Federal Medical Centre Umuahia, Nigeria \\ ${ }^{4}$ Department of Internal Medicine, Federal Teaching Hospital Abakaliki, Nigeria \\ ${ }^{5}$ Department of Internal Medicine, Abiastate University Teaching Hospital, Nigeria \\ ${ }^{6}$ Department of Medicine, Nnamdi Azikiwe University Teaching Hospital, Nigeria \\ ${ }^{7}$ Department of Medicine, Federal Medical Centre Owerri, Nigeria \\ ${ }^{8}$ Department of Medicine, Chukwuemeka Odumegwu Ojukwu Teaching Hospital, Nigeria
}

*Corresponding author: Theresa Nwagha, Thrombosis and bleeding unit, Department of Haematology \& blood transfusion, University of Nigeria Enugu Campus1/University of Nigeria Teaching Hospital Ituku Ozalla, Nigeria, Email: theresa.nwagha@unn.edu.ng

\section{Abstract}

Introduction: Therapeutic and prophylactic anticoagulation is under-prescribed in Nigeria, Dismal practice patterns of anticoagulation, lack of hospital-based anticoagulation policy may be contributory

Objective: The aim was to evaluate clinicians practice patterns in anticoagulation therapy and prophylaxis in Nigeria.

Materials and Methods: The study was a multi-centre survey using pretested validated questionnaire administered to 528 clinicians in some tertiary hospitals in South East Nigeria. The primary outcome measure was the practice pattern of anticoagulation therapy and prophylaxis. A p-value $<0.05$ was considered as statistically significant. Data analysis was with Statistical Package for Social Science (SPSS) software, version 18 (SPSS Inc., Chicago, IL)

Results: We discovered that only 52 respondents (9.8\%) claimed their institutions had an anticoagulation policy. The most prescribed anticoagulation agent was low molecular weight heparin (LMWH), (AOR 163, 95\% CI 0.85-0.3.14, $\mathrm{P}=0.19$ ) while the fondaparinux was least prescribed (AOR 1.74, 95\% CI 0.61-5.0 P=0.44). Only 193 (36.6\%) of the respondents routinely prescribed anticoagulation therapy when indicated. Those with 15-20 years clinical experience identified cost is an important determinant in prescribing anticoagulation agents. $(\mathrm{P}=0.06,95 \% \mathrm{CI} 0.94-12.4)$ 
Conclusion: The study showed the need to establish policy or guideline driven dedicated anticoagulation clinic services as well as practice-oriented CMEs to stem anticoagulation-related morbidity and mortality.

Keywords: Anticoagulation Therapy; Prophylaxis; Fondaparinux

Abbreviations: DOAC: Direct Acting Oral Anticoagulants; DVT: Deep-Vein Thrombosis; ICH: Intracranial Haemorrhage; PE: Pulmonary Embolism; SPSS: Statistical Package for Social Science; DAC: Dedicated Anticoagulation Clinics; AF: Atrial Fibrillation; OAC: Oral Anticoagulation; LMWH: Low Molecular Weight Heparin.

\section{Introduction}

Anticoagulants prevent the formation of thrombi that can form in the veins, arteries or intracardial with its attendant complications through obstruction, embolisation and consumption of haemostatic proteins [1]. The target-specific direct acting oral anticoagulants (DOAC) are more efficient and safer compared to older and widely used vitamin $\mathrm{k}$ antagonists (for example, warfarin) in the prevention of stroke and systemic embolism in patients with atrial fibrillation, and for the treatment of venous thromboembolism [2]. They do not require routine monitoring; they also do not have food or drug interactions [3]. The significant drawbacks of the DOACs include their high cost and lack of a specific antidote [3]. Though recently FDA has announced new reversal agents for dabigatran and rivaroxaban [4,5]. In the absence of anticoagulation therapy, the risk of deepvein thrombosis (DVT) in medically ill patients is comparable to that in moderate-risk surgical patients [6]. The decision to commence anticoagulation therapy usually involves the use of bleeding risk predictable outcome tools like HAS-BLED [7] (Hypertension, Abnormal renal function, abnormal liver function, Stroke Bleeding Labile INR, Elderly, Drugs) and CHA2D2S2-VASc ( Congestive cardiac failure, Hypertension, Age2 Diabetes, Stroke, Vascular disease, Sex female [8]. These guidelines ensure that patients who would benefit from anticoagulation, get them and excludes patients who will not find anticoagulants useful while keeping the incidence of complications like bleeding to the lowest tolerable level. Hence the decision to implement anticoagulant therapy in atrial fibrillation to improve outcome requires balancing the decreased risk of stroke against the increased risk for intracranial haemorrhage (ICH) [9].

Clagett, et al. showed that thrombo-prophylaxis reduced the risk of DVT and pulmonary embolism (PE)
[10]. There are also guidelines for the management of thromboembolic phenomenon which have been in place for many years, but anticoagulants remain underused throughout the world [11-13]. Centre for Outcomes Research at the University of Massachusetts Medical School (UMMS) conducted ENDORSE (Epidemiologic International Day for the Evaluation of Patients at Risk for Venous Thrombo-embolism in the Acute Hospital Care Setting) study. A cross-sectional survey of VTE risk and prophylaxis provision in the acute care hospital setting using data provided by 358 hospitals in 32 countries [14]. It showed a significant percentage of patients were at risk of DVT, but only $58.5 \%$ of at-risk surgical and $39.5 \%$ of atrisk medical patients received appropriate thromboprophylaxis [14]. Many other studies have supported these findings $[15,16]$. It is surprising that anticoagulants are still underutilised to this degree.

Previous studies have revealed grossly inadequate knowledge and a dismal practice of anticoagulation among healthcare workers $[7,8,17,18]$. The story is, however, different in North America were over 2 million people were either receiving or had benefited from anticoagulation as at 2012 [19]. Prophylactic anticoagulation is under-prescribed in South Africa, as well as in many countries in Africa [6]. Kesieme, et al. reported that $33.3 \%$ of surgeons had good knowledge of anticoagulation prophylaxis, while only $20 \%$ had a good practice of anticoagulation among the surgeons in tertiary hospitals in Nigeria [19].

The study aimed to evaluate the practice of anticoagulant therapy; determine anticoagulants agents used, the criteria for their prescription including which group of patients that will benefit from thromboprophylaxis. The study also documented the frequency of drug-induced complications resulting from the use of anticoagulants and if there is an anticoagulation policy in the hospitals surveyed.

\section{Methodology}

The present study was a multi-centre cross-sectional survey of the practice of anticoagulant therapy among clinicians in South East Nigeria from September 2016February 2017. Trained research assistants distributed 
Haematology International Journal

six hundred pretested multiple-choice self-administered questionnaires administered to clinicians (consultants specialist senior registrars, registrars and house-officers) in six tertiary hospitals in South East Nigeria. The questionnaire was to assess their practices in anticoagulation therapy. A pilot study checked for clarity and consistency of questions. The questionnaires were administered consecutively to clinicians in the participating centres. The following institutions participated in the survey: University of Nigeria Teaching Hospital Enugu, Federal Medical Centre Umuahia, Federal Teaching Hospital, Abakaliki, Abia State Teaching Hospital Aba, Nnamdi Azikiwe Teaching Hospital Nnewi, Federal Medical Centre Owerri and Chukwuemeka Odumegwu Ojukwu Teaching hospital, Amaku Awka. It was a twopart questionnaire and respondents were required to fill in their age, gender, number of years since graduating, speciality or grade and other parts consisted of questions on the practice of anticoagulation in their centres. We distributed anonymised questionnaires (omitting names of respondents and participating health institution) during clinical meetings, seminars, grand-rounds. Institution research ethics committee approved this study. We included tertiary healthcare institutions with residency training programme and excluded non-tertiary healthcare institutions without residency programme. Descriptive statistics with counts and percentages were used to illustrate the results. The data were also analysed using student t-test, and Fisher's exact test was used to detect any association between demographic profiles and anticoagulation practices patterns among respondents. A logistics analysis was used to detect any association between demographic background, practice patterns and anticoagulation management. A p-value $<0.05$ was statistically significant. Data analysis was with Statistical Package for Social Science (SPSS) software, version18 (SPSS Inc., Chicago, IL).

\section{Results}

\section{Practice Settings}

Of the six hundred questionnaires distributed, a total of 528 clinicians completed the questionnaires $(88 \%$ response rate). There were more males $378 / 528$ (71.6\%) than females, $150 / 528(28.4 \%)$ among the respondents. We showed that the clinicians who practised for fewer than5years are in the majority $189 / 528(35.8 \%)$ and those with 15-20years of practice $46 / 528(8.7 \%)$ are in the minority. The junior residents formed major part $164 / 528(31.1 \%)$, and the consultants are the least of the respondents 109/528 (20.6\%) (Table 1).

\begin{tabular}{|c|c|}
\hline Years of practice of respondents & Number (\%) \\
\hline$<5$ & $189(35.8)$ \\
\hline $6-10$ & $159(30.1)$ \\
\hline $11-15$ & $85(16.1)$ \\
\hline $16-20$ & $46(8.7)$ \\
\hline$>20$ & $109(20.6$ \\
\hline Grade of clinicians & \\
\hline House officers & $118(22.3)$ \\
\hline Junior residents & $164(31.1)$ \\
\hline Senior residents & $137(25.9)$ \\
\hline Consultants & $109(20.6)$ \\
\hline
\end{tabular}

Table 1: Some demographic characteristics of the respondents.

\section{Institution-Based Anticoagulant Policy and Use of Guidelines}

Only 498 out of 528 clinicians (94.3\%) responded to this query. The result showed that only 52 of 498 respondents $(10.5 \%)$ claimed their institutions had some form of anticoagulation policy and used guidelines in their practice. Only 274/494 (55.5\%) of them said they did not use guidelines and they had no such institutional anticoagulation policy, and 168 (34.0\%) responded "do not know" to that question.

\begin{tabular}{|c|c|}
\hline $\begin{array}{c}\text { Does your hospital have an } \\
\text { anticoagulation policy? }\end{array}$ & $\begin{array}{c}\text { Number of respondents } \\
\text { (percentage) }\end{array}$ \\
\hline Yes & $52(9.8 \%)$ \\
\hline No & $274(51.9 \%)$ \\
\hline Do not know & $168(31.2 \%)$ \\
\hline $\begin{array}{c}\text { Anticoagulation agents (AA) } \\
\text { prescribed }\end{array}$ & $511(96.8 \%)$ \\
\hline Unfractionated heparin & $502(95.1 \%)$ \\
\hline Warfarin & $406(76.9 \%)$ \\
\hline Low molecular weight heparin & $235(44.5 \%)$ \\
\hline NOAC & $222(42 \%)$ \\
\hline Fondaparinux & $492(93.2 \%)$ \\
\hline Complication & $109(20.6 \%)$ \\
\hline Bleeding & $5(0.9 \%)$ \\
\hline $\begin{array}{c}\text { Heparin-induced } \\
\text { thrombocytopenia }\end{array}$ & $4(0.8 \%)$ \\
\hline Osteoporosis & $1(0.2 \%)$ \\
\hline Skin necrosis & Nil \\
\hline Jaw necrosis & Nil \\
\hline Derangements of liver \\
enzymes
\end{tabular}

Table 2: Clinicians response to some questions on practice of anticoagulation. 
Table When there are no definite policies the practice of anticoagulation therapy and or prophylaxis are likely to be less than ideal with resultant increase in patient morbidity and mortality (Table 2).

\section{Clinicians Prescription Pattern Factors Affecting}

Clinicians used and prescribed low molecular weight heparin most frequently $(\mathrm{OR}=1.63,95 \% \mathrm{CI}=0.85-3.14$, $\mathrm{P}=0.44$ ) and fond aparinux was the most infrequently used (OR=1.74 95\% CI=0.61-5.0 $\mathrm{P}=<0.0001$ ) (Table 3).
The consultants prescribed heparin and warfarin most, with the newer anticoagulants taking the rear position. Only 193/521(37.0\%) of the respondents routinely prescribed anticoagulation therapy when indicated. Multinomial logistic regression showed that clinicians with $<5$ years of clinical practice; "don't feel it is important to prescribe anticoagulation therapy or prophylaxis when indicated" (P, 0.005 95\% CI, 1.3-3.7). Respondents with 15-20 years clinical practice identified cost is an essential variable in prescribing anticoagulation agent (P, 0.062 95\% CI, 0.94-12.4) (Tables 4-6).

\begin{tabular}{|c|c|c|c|c|c|}
\hline Clinicians who prescribed AA when & \multirow{2}{*}{$\begin{array}{c}\text { Anticoagulants } \\
\text { indicated }\end{array}$} & \multirow{2}{*}{ AOR } & \multirow{2}{*}{ P value } & \multicolumn{2}{|c|}{ 95\% CI } \\
\cline { 3 - 6 } & & & & Lower bound & Higher bound \\
\hline \multirow{2}{*}{ Consultants } & UF & 2.79 & 0.0006 & 1.57 & 4.94 \\
\cline { 2 - 6 } & Warfarin & 0.5 & 0.02 & 0.28 & 0.88 \\
\hline \multirow{3}{*}{ Non Consultants } & LMWH & 1.63 & 0.19 & 0.85 & 3.14 \\
\cline { 2 - 6 } & Fond aparinux & 1.74 & 0.44 & 0.6 & 5 \\
\cline { 2 - 6 } & NOACS & 0.94 & 1 & 0.46 & 1.9 \\
\hline
\end{tabular}

Table 3: Prescription pattern of anticoagulants among clinicians.

\begin{tabular}{|c|c|c|c|}
\hline \multirow{2}{*}{ Factors that affect prescription pattern } & \multicolumn{3}{|c|}{ Likelihood Ratio Tests } \\
\cline { 2 - 4 } & Chi-Square & df & P valve \\
\hline Do not feel it is important to prescribe & 14.738 & 4 & .005 \\
\hline Risk of prescription outweighs the benefit & 17.374 & 4 & .002 \\
\hline The cost is prohibitive & 12.564 & 4 & .32 \\
\hline It is not a policy of our hospital & 4.694 & 4 & .089 \\
\hline $\begin{array}{c}\text { My seniors gives contrary instruction on } \\
\text { prescription }\end{array}$ & 8.067 & 4 & 4 \\
\hline
\end{tabular}

Table 4: Factors that affects Clinicians prescription pattern of anticoagulation agents.

\begin{tabular}{|c|c|c|c|c|c|}
\hline \multirow{2}{*}{$\begin{array}{l}\text { Years of } \\
\text { practice }\end{array}$} & \multirow{2}{*}{ Factors that affects prescription pattern } & \multirow{2}{*}{$P$ value } & \multirow{2}{*}{$\operatorname{Exp}(B)$} & \multicolumn{2}{|c|}{$\begin{array}{l}\text { 95\% Confidence Interval } \\
\text { for } \operatorname{Exp(B)}\end{array}$} \\
\hline & & & & Lower Bound & $\begin{array}{l}\text { Upper } \\
\text { Bound }\end{array}$ \\
\hline \multirow{5}{*}{$<5$} & Don't feel it is important to prescribe & .003 & 2.203 & 1.300 & 3.731 \\
\hline & Risk of prescription outweighs the benefit & .262 & .632 & .283 & 1.409 \\
\hline & The cost is prohibitive & .457 & .549 & .489 & 4.905 \\
\hline & It is not a policy of our hospital & .358 & .593 & .195 & 1.806 \\
\hline & My seniors' gives contrary instruction on prescription & .822 & .871 & .263 & 2.891 \\
\hline \multirow{5}{*}{05 -Oct } & Don't feel it is important to prescribe & .026 & 1.832 & 1.074 & 3.123 \\
\hline & Risk of prescription outweighs the benefit & .577 & 1.25 & .57 & 2.741 \\
\hline & The cost is prohibitive & .423 & 1.615 & .501 & 5.211 \\
\hline & It is not a policy of our hospital & .799 & .864 & .281 & 2.655 \\
\hline & My seniors' gives contrary instruction on prescription & .052 & .215 & .045 & 1.017 \\
\hline \multirow{4}{*}{ Oct-15 } & Don't feel it is important to prescribe & .673 & 1.132 & .635 & 2.018 \\
\hline & Risk of prescription outweighs the benefit & .523 & .748 & .307 & 1.823 \\
\hline & The cost is prohibitive & .014 & 4.292 & 1.338 & 13.762 \\
\hline & It is not a policy of our hospital & .789 & 1.174 & .364 & 3.792 \\
\hline
\end{tabular}


Haematology International Journal

\begin{tabular}{|c|c|c|c|c|c|}
\hline & My seniors' gives contrary instruction on prescription & $\mathbf{. 0 7 6}$ & .199 & .033 & 1.187 \\
\hline $15-20$ & Don't feel it is important to prescribe & .145 & 1.642 & .843 & 3.2 \\
\hline & Risk of prescription outweighs the benefit & .129 & .404 & .126 & 1.302 \\
\hline & The cost is prohibitive &. $\mathbf{0 6 2}$ & $\mathbf{3 . 4 1 5}$ &. $\mathbf{9 3 9}$ & $\mathbf{1 2 . 4 1 5}$ \\
\hline & It is not a policy of our hospital & .985 & .987 & .257 & 3.79 \\
\hline & My seniors' gives contrary instruction on prescription & .174 & .209 & .022 & 1.997 \\
\hline
\end{tabular}

Table 5: Multinominal logistics analysis of factors that affects prescription patters based on years of practice.

\begin{tabular}{|c|c|}
\hline Reason & Number of respondents(percentage) \\
\hline Do not feel it is important to prescribe & $484(91.7 \%)$ \\
\hline Risk of prescription outweighs the benefit & $412(78 \%)$ \\
\hline The cost is prohibitive & $439(83.1 \%)$ \\
\hline It is not a policy of our hospital & $469(88.8 \%)$ \\
\hline My seniors give contrary instruction on prescription & $492(93.2 \%)$ \\
\hline
\end{tabular}

Table 6: Showing reasons why clinicians do not prescribe anticoagulation prophylaxis routinely as required.

\section{Anticoagulation Management}

Anti-coagulation treatment and prophylaxis were the most frequently used for patients with prolonged surgery $168 / 520(32.3 \%)$. Sixty-three percent of respondents $63 / 520$ (12.5\%) were unsatisfied while 219/504 (43.4\%) were not very satisfied with the laboratory monitoring tools available in their institutions. Bleeding was the most common complication of anticoagulation among the respondents 383/492(77.9\%). The least encountered complication was jaw necrosis 57/479 (11.9\%).

\section{Discussion}

The non-existent anticoagulation policy in our various healthcare institutions and disuse of anticoagulation management practice guidelines in Nigeria is probably responsible for the less than ideal standard care received by Nigerians needing anticoagulation. The few anticoagulation services available appear not to be protocol or guideline-driven, unorganised, poorly funded, and inadequately equipped. Anticoagulation policies help define and guide the establishment and success of dedicated anticoagulation clinics (DAC). Lack of hospitalbased anticoagulation policies have led to no dedicated anticoagulation services or where offered, are substandard and not according to best practices. In Nigeria, observational evidence and experiences from most clinicians in tertiary healthcare institutions are that absence of dedicated anticoagulation clinics in their centres. However, some sub-Saharan African countries now have DAC notably Kenya and South Africa [20,21]. A well-articulated anticoagulation policy could have pharmacists, nurses and family physicians manage DAC under the supervision of haematologists and or cardiologists.

In our survey, we also found that there was a low number of the respondents who routinely prescribed anticoagulation therapy when indicated in this study. A probable reason for this unsafe practice may be the fear of bleeding, which is the most frequent complication of anticoagulation therapy inform the hospitals included in this survey. No doubt, bleeding from over anticoagulation is a real danger, but it is worse where there is no dedicated anticoagulation clinic and suboptimal blood transfusion support. The low prescription rate in this survey was also in keeping with the belief of the respondents that the risk of anticoagulation outweighs the benefits and strengthened by the acceptance that the cost was an important variable in prescribing anticoagulation agents. It may not come as a surprise that few respondents were favourably disposed to prescribing anticoagulants given that majority of them reported that their institutions had no anticoagulation policy.

Unfractionated heparin was the most frequently, and fond aparinux was the most infrequently prescribed for therapeutic and prophylactic indications among the clinicians. The plausible reason may be that NOACsis still relatively unknown in our environment and not readily available and accessible. NOAC is also more expensive than conventional anticoagulants. Continuous medical education, together with viable insurance schemes that will discourage out of pocket spending by patients may improve the prescription of NOACs for anticoagulation treatment and prophylaxis. 
Understandably, prolonged surgery, the risk of DVT and immobilisation form the highest indications for the prescription of anticoagulants in the centres surveyed. Atrial fibrillation (AF), rheumatic heart disease and mechanical valves and atrial fibrillation (AF) were the least indications for anticoagulation among clinicians in this study. AF remains one of the major causes of stroke, heart failure, sudden death, and cardiovascular morbidity in the world [22]. Current guidelines state that oral anticoagulation (OAC) is a cornerstone therapy in the management of AF. Surprisingly, heart failure was not on the list of indications for the prescription of anticoagulants despite its high prevalence in the subSaharan African countries [23]. Heart failure and AF coincide in many patients [24-26]. They are also linked to similar risk factors and share a common pathophysiology [27]. Heart failure with reduced ejection fraction has increased the risk of thromboembolic events. The use of $\mathrm{OAC}$ in heart failure with $\mathrm{AF}$ is not debatable, but their use in heart failure in sinus rhythm has been contentious [28]. The current consensus is that there is no convincing data to support the use of anticoagulation with VKAs because of the increased rate of bleeding among these patients even though that VKAs significantly reduced the rate of ischaemic strokes [29-32].

Anticoagulation has been shown to be important, appropriate and capable of reducing complications among the rheumatic heart disease populations. Fleming, et al. showed a marked reduction of VTE incidents in patients with rheumatic heart disease compared to untreated patients with RHD [31]. Although the clear benefits of VKA therapy in patients with RHD, very few patients have access to systematic anticoagulation management in resource-constrained settings where RHD is most prevalent $[33,34]$.

No respondent mentioned HIV as an indication for anticoagulation in this survey. Currently millions of patients throughout sub-Saharan Africa are now receiving care for HIV [22]. Previous investigations have revealed an almost four-fold increase in the risk for DVT among HIV-infected populations compared to general populations [22]. As HIV care programs continue to grow and expand throughout sub-Saharan Africa, there must also be a focus on developing the infrastructure for many of the complementary aspects of HIV care, such as anticoagulation monitoring to ensure patients have access to all essential aspects of care [35].

Bleeding is a significant adverse effect of anticoagulation. Our survey showed the trepidation which is associated with bleeding as almost all respondents chose this option as the main drawback to anticoagulation. A significant concern expected when there is no anticoagulation policy and no dedicated anticoagulation clinic available. In fact, centres with DAC have low complications and manage such complications. A South African study, showed a low incidence of bleeding complications in a study population, some of the bleeding episodes resulted from drug-drug interactions [23]. The prevalence of significant bleeding associated with the use of LMWH for prophylaxis and VTE treatment is low compared to other anticoagulant agents like UFH, fond aparinux [36-39].These data suggest a manageable incidence of bleeding in centres with DAC. The concern for bleeding should not deny patients in need of anticoagulation, the benefits of life-saving effects of anticoagulants.

Globally, management of anticoagulation therapy presents a significant problem for clinical and laboratory services [38], only a DAC can match such challenges. The issue of cost also impacts negatively on the practice of anticoagulation. In the background of poor socioeconomic factors and infantile medical insurance scheme, with many uninsured, out of pocket expense continuously hinders patients' compliance and adherence to the use of anticoagulants especially the NOACs [39].

\section{Conclusion}

This survey has shown the lack of anticoagulation policies and use of anticoagulation guidelines among the centres that participated. The practice of anticoagulation must follow international guidelines and best practices to be beneficial to patients. Our survey has also shown deficiencies in practice patterns of the clinicians for anticoagulation therapy in South East Nigeria. These gaps can be remedied by continuous medical education, by the establishment of anticoagulation policies and guidelinedriven dedicated anticoagulation clinics (DAC).

\section{References}

1. Anakwue RC, Ocheni S, Madu AJ (2014) Utilisation of oral anticoagulation in a teaching hospital in Nigeria. Ann Med Health Sci Res 4: 286-290.

2. Arepally GM, Ortel TL (2015) Changing practice of anticoagulation: Will target-specific anticoagulants replace warfarin? Annu Rev Med J 66: 241-253.

3. Connolly SJ, Ezekowitz MD, Yusuf S (2009) RE-LY Steering committee and Investigators: Dabigatran versus warfarin in patients with atrial fibrillation. $\mathrm{N}$ Engl J Med 361: 1139-1151. 
4. Pollack CV, Paul A Reilly, Joanne van Ryn, John W Eikelboom, Stephan Glund, et al. (2015) Idarucizumab for Dabigatran Reversal. N Engl J Med 373: 511-520.

5. Siegel, John T Curnutte, Stuart J Connolly, Genmin Lu, Pamela B Conley, et al. (2015) Andexanet Alfa for the Reversal of Factor Xa Inhibitor Activity. N Engl J Med 373: 2413-2424.

6. Jacobson BF, Louw S, Buller H, Mer M, de Jong PR, et al. (2013) Venous thromboembolism: Prophylactic and therapeutic practice guidelines. South Afri Med J 103(4): 260-267.

7. Pisters R, Lane DA, Nieuwlaat R, Crijins HJ, Lip GY (2010) A novel user-friendly score (HAS-BLED) to assess one year risk of major bleeding in atrial fibrillation patients. The Euro Heart Survey Chest 138(5): 1093-1100.

8. Camm AJ, Lip GY, De Caterina R (2012) Updates of the 2010 European Society of Cardiology guidelines for the management of atrial fibrillation. Europace 14: $1387-413$

9. Merli G Weitz H (2006) The Decision to Anticoagulate: Assessing whether Benefits Outweigh the Risksfor Patients with Atrial Fibrillation You have free access to this content Clinical Cardiology. 27(6).

10. Clagett GP, Anderson Jr FA, Levine MN, Salzman EW, Wheeler HB (1992) Prevention of venous thromboembolism. Chest 102(5): 391-407.

11. Greets WH, Pineo GF, Heit JA (2004) Prevention of venous thromboembolism: the Seventh ACCP Conference on Antithrombotic and thrombolytic Therapy. Chest 126(3): 338-400.

12. Yu HT, Dylan ML, Lin J, Dubois RW (2007) Hospital's compliance with prophylaxis guidelines for venous thromboembolism. Am J Health Sys Pharm 64(1): 6976.

13. Cohen AT, Tapson VF, Bergmann JF, Goldhaber SZ, Kakkar AK, et al. (2008) Venous Thromboembolism risk and orophylaxis in acute hospital care setting (ENDORSE study): a multinational cross sectional study. Lancet 371(9610): 387-394.

14. Akbar MN, Salahuddin O, Zafarullah O (2006) A clinical audit on venous thromboembolism prophylaxis of medical patients in West Medical Ward, Mayo Hospital. Ann King Edward Med Uni 12(2): 328-330.
15. Bilal N (2001) Prophylactic anticoagulation for perioperative deep venous thrombosis. J Pak Inst Med Sci 8: 603-605.

16. Kimmerly WS, Sellers KD, Deitcher SR (1999) Graduate surgical trainee attitudes toward postoperative thromboprophylaxis. South Med J 92(8): 790-794.

17. Bhati AM, Ahsin S, Salim B, Mansoor J (2012) Knowledge, Attitude and Practices of healthcare providers toward deep-vein thrombosis prophylaxis in five teaching hospitals of Rawalpindi. J Ayub Med CollAbbottabad 24: 136-139.

18. Guyat GH, Akl EA, Crowther M, Gutteman DD, Schuunemann HJ (2012) American College of Chest Physicians Antithrombotic Therapy and Prevention of Thrombosis Panel. Executive Summary; 9thed: American College of Chest Physicians Evidence-based Clinical Practice Guidelines. Chest 141: 7-47.

19. Kesieme EB, Arekhandia BJ, Inuwa IM, Akpayak IC, Ekpe EE, et al. (2016) Knowledge and Practice of prophylaxis of deep-vein thrombosis: A survey among Nigerian surgeons. Niger J Clin Pract 19(2): 170-174.

20. Sonuga BO, Hellenberg DA, Cupido CS, Jaeger C (2016) Profile and anticoagulation outcomes of patients on warfarin therapy in an urban hospital in Cape Town, South Africa. Afr J Prim Health Care Fam Med 8(1): 1032.

21. Pastakia SD, Crisp WI, Schellhase EM (2010) Implementation of a pharmacist managed anticoagulation clinic in Eldoret, Kenya. Southern Med Review 3(2): 20-23.

22. Paulus Kirchhof, Stefano Benussi, Dipak Kotecha (2016) 2016 ESC Guidelines for the management of atrial fibrillation developed in collaboration with EACTS Eur Heart J 37(38): 2893-2962.

23. Guha K, McDonagh $T$ (2013) Heart failure epidemiology: European perspective. Curr Cardiol Rev 9(2): 123-127.

24. Braunschweig F, Cowie MR, Auricchio A (2011) What are the costs of heart failure? Europace 2: 13-17.

25. Wodchis WP, Bhatia RS, Leblanc K, Meshkat N, Morra D (2012) A review of the cost of atrial fibrillation. Value Health 15(2): 240-248. 
26. Kotecha D, Piccini JP (2015) Atrial fibrillation in heart failure: what should we do? Eur Heart J 36(46): 3250 3257.

27. Tsao A (2015) Anticoagulation in heart failure in Sinus Rhythm. Expert analysis for American College of Cardiology.www.acc.org/latest in cardiology.

28. Lip GY, Ponikowski P, Andreotti F, Anker SD, Filippatos G, et al. (2012) Thrombo-embolism and antithrombotic therapy for heart failure in sinus rhythm. A joint consensus document from the ESC Heart Failure Association and the ESC Working Group on Thrombosis. Eur Heart J Heart Fail 14(7): 681-695.

29. Lip GY, Gibbs CR (2002) Anticoagulation for heart failure in sinus rhythm: a Cochrane systematic review. QJM 95(7): 451-459.

30. Rengo G, Pagano G, Squizzato A, Moja L, Femminella GD, et al. (2014) Oral anticoagulation therapy in heart failure patients in sinus rhythm: a systematic review and meta-analysis. PLOS ONE 8: e52952.

31. Fleming HA (1971) Anticoagulants in rheumatic heart-disease. Lancet 2: 486.

32. Isma'eel H, Zebian R, El-Accaoui R, Dimassi A, Rashid $\mathrm{K}$, et al. (2007) Anticoagulation clinics are needed in developing countries. Int J Card 115(3): 410-411.

33. Bendavid E, Bhattacharya J (2009) The President's emergency plan for AIDS relief in Africa: an evaluation of outcomes. Ann Intern Med 150(10): 688-695.
34. Freedman KB, Brookenthal KR, Fitzgerald RH, Williams S, Lonner JH (2000) A meta-analysis of thromboembolic prophylaxis following elective total hip arthroplasty. J Bone Joint Surg Am 82(7): 929938.

35. Mismetti P, Quenet S, Levine M, Merli G, Decousus H, et al. (2005) Enoxaparin in the treatment of deep vein thrombosis with or without pulmonary embolism: an individual patient data meta-analysis. Chest 128(4): 2203-2210.

36. Turpie AG, Bauer KA, Eriksson BI, Lassen MR (2002) Fondaparinux vs enoxaparin for the prevention of venous thromboembolism in major orthopedic surgery: a meta-analysis of 4 randomized doubleblind studies. Arch Intern Med 162(16): 1833- 1840.

37. Buller HR, Davidson BL, Decousus H, Gallus A, Gent M, et al. (2004) Fondaparinux or enoxaparin for the initial treatment of symptomatic deep venous thrombosis: a randomized trial. Ann Intern Med 140(11): 867-873.

38. Mortimer C, Cottrell W, Comino J (2005) Automatic drug use audit in primary care: a pilot evaluation of warfarin use for patients with atrial fibrillation. Aust J Fam Physician 34(9): 798-800.

39. Kirley K, Rao G, Bauer V, Masi C (2016) The Role Of NOACs in Atrial Fibrillation Management: A Qualitative Study. J Atr Fibrillation 9(1): 1416. 